\title{
Spatial and temporal patterns in the diet of the Andean condor: ecological replacement of native fauna by exotic species
}

\author{
S. A. Lambertucci ${ }^{1}$, A. Trejo $^{2}$, S. Di Martino ${ }^{3}$, J. A. Sánchez-Zapata ${ }^{4}$, J. A. Donázar ${ }^{5}$ \& F. Hiraldo \\ 1 Department of Ecology, Ecotono Laboratory, INIBIOMA-CONICET, Universidad Nacional del Comahue, Bariloche, Argentina \\ 2 Department of Zoology, Universidad Nacional del Comahue, Bariloche, Argentina \\ 3 Natural Protected Areas of Neuquén, Junín de los Andes, Neuquén, Argentina \\ 4 Department of Applied Biology, Universidad Miguel Hernández, Orihuela, Alicante, Spain \\ 5 Department of Conservation Biology, Estación Biológica Doñana, CSIC, Sevilla, Spain
}

Keywords

dietary shift; food source; human impacts; invasive species; Patagonia; scavengers; Vultur gryphus.

\section{Correspondence}

Sergio A. Lambertucci, Department of Ecology, Ecotono Laboratory, INIBIOMACONICET, Universidad Nacional del Comahue, Quintral 1250, Bariloche, R 8400 FRF, Argentina.

Emails: slambertucci@crub.uncoma.edu.ar; slambertucci@gmail.com

\begin{abstract}
The development of conservation strategies to protect viable populations of scavenging birds requires the existence of adequate and safe food supplies in the wild. Early reports on Andean condors Vultur gryphus diet recorded guanacos and rheas, the dominant herbivores since the Pleistocene, as their main food in Patagonia. However, in the past century, guanaco and rhea populations have notably decreased as a consequence of introduced livestock, and other exotic mammals have colonized the region. We study the spatial and temporal variation of the condors' diet to determine which species are being consumed by condors, and to test whether native herbivores still have a role as a food source. We analysed 371 pellets (517 prey items), collected along $500 \mathrm{~km}$ in northwestern Patagonia, Argentina. Our study shows that the Andean condor depends heavily (98.5\%) on exotic herbivores. Their diet was made up of c. 51\% sheep/goat, 24\% hare/rabbit, $17 \%$ red deer and $6 \%$ cow/horse, with only $2 \%$ other mammal species. Samples from locations surveyed after 12-15 years showed a diet shift coincident with the local tendencies in the food source. The diet composition of condors using roosts within the same zone was very similar, which suggests that they may be feeding from the same area. Thus, unhealthy carcasses could impact the entire local populations. Our results show the abundance of the invasive species in northwestern Patagonia and support the idea that native mega-herbivores are ecologically extinct in this area. Exotic species management can have a decisive impact on scavenger's survival. It is necessary to apply a strategy that includes public environmental education about the problems of scavengers (e.g. use of poison, veterinary medicines and lead bullets), and a serious productive plan, including native species as a suitable source of economic development.
\end{abstract}

\section{Introduction}

Human changes in land use have wide impacts on ecosystems. Modification of landscapes throughout the world produces profound effects on wildlife, but on particular species, several of these impacts still remain unknown (Foley et al., 2005; Harveson et al., 2007). The increase of livestock may benefit raptors, and particularly scavengers, by supplementing their food resources, and may also modify their feeding habits (Donazar, 1993; Sanchez-Zapata et al., 2003). However, livestock can generate new threats for raptors and scavengers associated with drugs supplied to treat illnesses or poisons used to reduce predation on livestock (Oaks et al., 2004; Blanco et al., 2007; Carrete et al., 2007; Lemus et al., 2008). Moreover, human activities may promote the introduction and may widen the distribution range of exotic species, which represent new food sources, but also new threats (Jaksic, 1998; Zavaleta, Hobbs \& Mooney, 2001; Foley et al., 2005).

Argentine Patagonia, proposed as one of the 'Earth's Last Wild Places', has undergone important changes in the number and composition of its mega-fauna during the 20th century (see Walker et al., 2005). Native lesser rheas Rhea pennata (a flightless $20-25 \mathrm{~kg}$ bird) and guanacos Lama guanicoe (a 100-200 kg camelid) have decreased drastically, mainly due to human persecution, competition with livestock and other exotic species, and habitat degradation from overgrazing by sheep (Baldi, Albon \& Elston, 2001; Novaro \& Walker, 2005). Before European colonization, guanaco 
numbers in Patagonia were estimated at seven to 20 million, but a mere $2-9 \%$ of the original population has been estimated in recent times (Amaya, von Thungen \& De Lamo, 2001; Novaro \& Walker, 2005). Comparison of current density estimates for lesser rheas in Patagonia with records of the early explorers also suggests a widespread collapse of their population (see the review in Novaro \& Walker, 2005). Livestock (mainly sheep, but also cattle, goats and horses) were introduced into Patagonia as early as the $1500 \mathrm{~s}$, reaching current figures of about 8.5 million sheep, 0.86 million goats, 0.82 million cows and 0.16 million horses (INDEC, 2002). During the last two centuries, other exotic species that have been introduced into Patagonia for hunting and/or ornamental purposes (Grigera \& Rapoport,1983; Jaksic,1998), such as the red deer Cervus elaphus, wild boar Sus scrofa and lagomorphs (European hare Lepus europaeus, and rabbits Oryctolagus cuniculus), have notably increased in number (see Novillo \& Ojeda, 2008 for a review). Changes in the abundance of exotic species may influence ecologically similar native species, but can also strongly modify the food web, resulting in new relationships that could favour the ecological extinction of native species (Jaksic,1998; Novaro, Funes \& Walker, 2000).

The Andean condor Vultur gryphus is a worldwide Near Threatened species, but it is critically endangered in the north of its distribution, is listed in CITES Appendix I and is negatively affected by human disturbances (International Union for the Conservation of Nature, 2007; Lambertucci, 2007; Speziale, Lambertucci \& Olson, 2008; Lambertucci et al., 2009). Along its entire distribution in the South American Andes Range, the reasons for the declining populations are all directly or indirectly human related. The condor is also a very vulnerable species due to several characteristics of its natural history such as great longevity, very low reproductive rates, dependence on high survival rates and gregariousness when roosting and eating (Lambertucci, 2007). The Andean condor is a large, scavenging bird (13 kg mass, $3 \mathrm{~m}$ wingspan and $1.3 \mathrm{~m}$ height, Ferguson-Lees \& Christie, 2001) that feeds mainly on carcasses of mediumto large-sized vertebrates (Wallace \& Temple, 1988). In Patagonia, historical reports during the 1800s recorded condors feeding on guanacos and lesser rheas (e.g. Darwin, 1921; Moreno, 1969; Musters, 2005), the dominant herbivores of the region since the Pleistocene extinctions (Novaro \& Walker, 2005). Although some reports on condors consuming carcasses of exotic species exist (e.g. Wallace \& Temple, 1987a; Donazar et al., 1999; Rios-Uzeda \& Wallace, 2007; Lambertucci et al., 2009), at present, there are no specific studies that account for the diet of this species.

The development of conservation strategies to protect viable condor populations must include an analysis of the existence of adequate and safe food supplies in the wild for these birds (Chamberlain et al., 2005). Changes in the composition of the fauna can be represented in the condor's diet and these dietary shifts can have important implications for their conservation (Chamberlain et al., 2005). The knowledge of both the condors' degree of opportunism and the dependence on managed animals is very important, given that management of domestic and wild animals is highly variable. This management may represent several threats for condors associated with either drugs and poisoning to protect livestock or with lead from hunting wild exotic populations. Although foraging group structure and strategies have been studied before (Donazar et al., 1999; Speziale et al., 2008), detailed information on this bird's diet and its temporal and spatial variation is scarce or lacking, and is based mostly on direct observations of animals at carcasses (e.g. Wallace \& Temple, 1988).

The purpose of this work is to study the spatial and temporal variation of the Andean condors' diet, in order to know which species different condor populations are consuming, and to indirectly test whether native herbivores still have a role as a food source in northwestern Patagonia. We pay special attention to variations in the composition and proportion of exotic and native species in the condors' diet. In order to achieve our goal, we compare the variation in the diet among 11 sites, and the temporal change at two places after more than a decade. The results of this work may help researchers and managers to focus on current threats related to the Andean condor's food sources and habitat, allowing in turn the development of a structured conservation plan.

\section{Methods}

\section{Study area}

The study area is located in northwestern Patagonia in the southern tip of South America (in a c. $25000 \mathrm{~km}^{2}$ between latitude 361-411S and longitude 701-711W, Fig. 1a). The climate is cold-temperate, with frost throughout the year, frequent snowfall in winter and with summer being the driest season (Paruelo et al., 1998). The geological history, along with the more recent erosive processes, has created a large number of cliffs that are used by the local fauna (Giacosa et al., 2005).

The area consists of a gradient that encompasses two major biogeographic units, the Subantarctic forest and the steppe, and the ecotone between these two units (Paruelo et al., 1998). The ecotone and the steppe areas have been used for extensive livestock ranching mainly since the last century, and is also one of the regions in Argentina that received the greatest amount of alien mammal introductions, including the red deer, wild boar, European hare and rabbit (Baldi et al., 2001; Novillo \& Ojeda, 2008). At the centre of the study area, Neuquen province, the mean value of sheep and cattle/horses was estimated at 26.3 and 4.9 individual $\mathrm{km}^{-2}$, respectively, during 1989-1994 (Novaro et al., 2000). Over the past decades, sheep populations have declined, but still remain in high densities (Amaya et al., 2001). Red deer populations have increased from 1.6 in$\mathrm{d} \mathrm{km}^{-2}$ during 1992-1994 (Novaro et al., 2000) to a mean of 12.6 individual $\mathrm{km}^{-2}$ at present (J. Sanguinetti, pers. comm.; M. Monteverde, pers. comm.; range 5.5-24 individual $\mathrm{km}^{-2}$ depending on the farm). European hare densities were estimated at 47.5 individual $\mathrm{km}^{-2}$ during 1991-1994 (Novaro et al., 2000), but no current data are available for this 


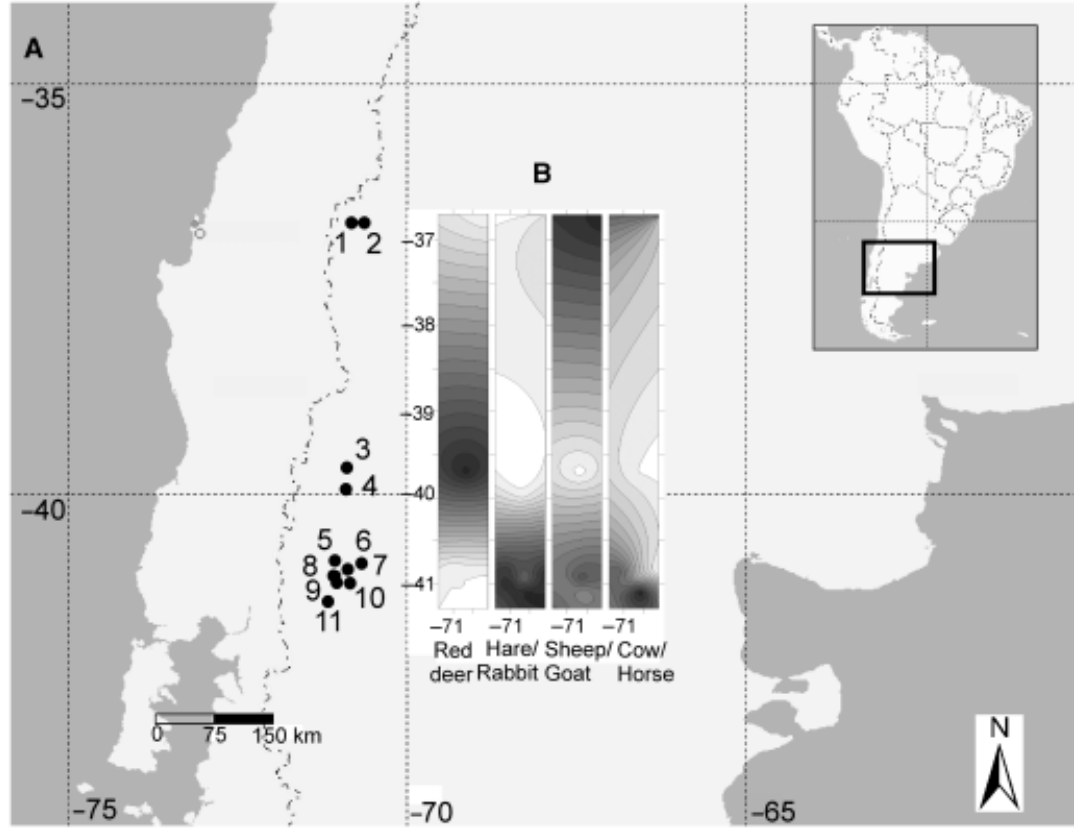

Figure 1 (a) Study area in northern Patagonia, Argentina, showing the 11 locations (black dots, Andean condor communal roosts) surveyed (see Fig. 2 for correspondence of numbers and names of the places surveyed). (b) An isoline map modelling the spatial variation of the four main prey items abundance in the condor's diet along the study area (for more details see the main text). The darker colour represents greater consumption of the species in that area. area. Native mega-herbivores have decreased in the last two decades from c. 2.2 individual $\mathrm{km}^{-2}$ (1982) to 1 individual $\mathrm{km}^{-2}$ (2001-2002) of guanacos, and from c. 2.3 individual $\mathrm{km}^{-2}$ (1982) to 0.3 individual $\mathrm{km}^{-2}$ (2000) of lesser rheas (see the review in Novaro \& Walker, 2005). Legal hunting of deer and hares in the entire study area has increased in recent years.

\section{Diet analyses}

In this area, Andean condors select cliffs, used as communal roosts, to overnight every day (see Lambertucci, Jacome \& Trejo, 2008). We collected the sample pellets from these cliffs to analyse the composition of the diet (Fig. 1a). Pellets were collected at 11 communal roosts within an area of c. $500 \times 50 \mathrm{~km}$. Distances between communal roosts were around $1 \mathrm{~km}$ between Covunco and Guanaco, $30 \mathrm{~km}$ between Huechahue and Remolinos and $28 \mathrm{~km}$ in average in the southern places (range 5-62 km). We collected the pellets in the summers of 1992-1995 at two roosts (Huechahue and Remolinos) and in the summer of 2007 at all 11 roosts. All pellets were dissected under a stereoscopic microscope with the aid of forceps. Mammal carrion was identified by the appearance and structure of hair remains using identification keys (Chehebar \& Martin, 1989; De Marinis \& Asprea, 2006). Feathers were identified by comparison with a reference feather collection. In some cases, we did not distinguish between sheep and goat hair, or between horse and cow hair, and so we pooled the results for each pair of species.

\section{Statistical analyses}

We expressed our results on the diet composition for each communal roost as a percentage of total prey (representing the number of times each item was encountered in relation to the total number of items in all pellets), and percentage occurrence of each item in relation to the total number of pellets. We did not express our results in terms of biomass because it is difficult to determine this parameter for carrion in the diet. Given the inaccuracy resulting from estimating the number of individual prey from carrion-eaters' pellets, we expressed our results as percentage occurrence in relation to the total number of pellets in all subsequent analyses. An isoline map was elaborated to model and to graphically show the spatial variation of the main prey item abundances in the condors' diet along the study area. For this we elaborated a continuous surface of interpolated data over the total extent of the study area, relating the percentage occurrence of a prey item to the coordinates of each place from where we collected the pellets. Contour lines were obtained using a geostatistical technique that uses an estimation of the semivariance of the data to perform interpolations ('kriging': see Matheron, 1963).

We performed cluster analysis to group communal roosts taking into account similarities in the diet composition. This analysis groups similar entities together into hierarchical classes (Gauch, 1999). Ward's method was used to partition the data. This method uses an analysis of variance approach to compare any two clusters that can be formed at each step (for details, see Ward, 1963). Additionally, we evaluated whether the composition of the diet was more similar in communal roosts close to each other, by comparing a matrix of the proportion of prey items for each communal roost and a matrix of the geographic distances between those roosts with a Mantel permutation test with 10000 randomizations (Bonnet \& Van de Peer, 2002). Dissimilarities in the diet composition were calculated as the Euclidean distances between each pair of communal roosts, based on the 
proportion of prey items for each place. Therefore, linear geographic distances between each pair of roosts were calculated using the Earth software (Byers, 1997).

To detect temporal changes in the diet composition, we used the 1992-1995 sample of pellets from two of the localities surveyed (Huechahue and Remolinos), and compared it with the food item categories in pellets collected during summer 2007 at the same roosts. We applied a w $w^{2}$ test to compare the overall change in the diet composition between years at a significance level of PO0.05.

\section{Results}

\section{Spatial variation in the diet}

We identified 517 prey items in 371 pellets collected from the 11 Andean condor communal roosts in 2007. Almost all the food ( $98.5 \%$ of the total prey) eaten by condors consisted of exotic species. Considering the total sample, the most important prey were sheep/goats, followed by lagomorphs (mostly hares), red deer and cows/horses (Table 1). Condors also consume negligible quantities of carrion of other species, such as medium-sized native mammals (mostly foxes and armadillos), guanacos and exotic wild boar (Table 1). We also found bird feathers (3.2\% of the pellets) that, in some cases, were attributed to lesser rheas, but were mostly attributed to condors. Given the similarity in the feather structure in the two species (A. Trejo, pers. obs.), we did not include these occurrences as prey.

We found that the four most frequently consumed groups of species were differentially eaten throughout the study area (Table 1; Fig. 1b). Red deer was basically consumed in the centre of the area, sheep/goats mainly in the northern extreme, but also in the south, and lagomorphs and cow/ horse mainly in the south (Fig. 1b). Sheep and goats constituted, on average, half of the food items found in the samples. In instances where we distinguished between sheep and goat hair $(79 \%$ of the total samples containing sheep and/or goat hair), hair corresponded to $84 \%$ sheep and $16 \%$ goat.

The dendrogram obtained showed three main clusters based on the diet composition (Fig. 2). The first bifurcation separated two groups of places that are the two communal roosts located in the centre of the study area (cluster 1: Huechahue and Remolinos), and the northern and southern communal roosts (clusters 2-3), indicating that Andean condors have a dissimilar diet composition in those areas. Inside the second group (clusters 2-3), the first bifurcation separated the northern communal roosts (cluster 2: Guanaco and Covunco) from the southern ones (cluster 3: Condorerita, Fragua Chica, Fragua Grande, Pichileufu, Buitrera, Pipilcura and Chaquenita; Fig. 2). The diet composition between neighbouring places tended to be more similar than randomly expected (Mantel test, $r=0.48$, $\mathrm{P}=0.025)$.

\section{Temporal variation in the diet}

We analysed samples of both places (Huechahue and Remolinos) together as they are next to each other, allowing condors to easily move between them, and spatial analysis revealed a similar diet composition. Thus, we analysed 172 pellets from 1992 to 1995 and we compared them with 93 pellets from 2007. Overall changes in the diet after $12-15$ years were clearly significant $\left(w_{7}^{2}=1052.0\right.$, PO0.001). We observed changes in the diet composition related to the amount of red deer, goat/sheep, guanaco and lagomorphs consumed (Fig. 3). The most remarkable difference was an increase in the consumption of red deer $\left(w^{2}=978.3\right.$, Po 0.001). Other changes included a decrease mainly in the consumption of sheep/goat $\left(w_{1}^{2}=54.6\right.$, PO0.001), guanaco $\left(w_{1}^{2}=10.5, P=0.001\right)$ and lagomorphs $\left(w_{1}^{2}=6.1\right.$, $\mathrm{P}=0.014)$.

Table 1 Summer 2007 diet composition in 11 localities situated on a north-south transect in northwestern Patagonia

\begin{tabular}{|c|c|c|c|c|c|c|c|c|c|c|c|c|c|c|c|c|}
\hline \multirow[b]{2}{*}{ Roost } & \multicolumn{2}{|c|}{ Sheep/goat } & \multicolumn{2}{|c|}{ Red deer } & \multicolumn{2}{|c|}{ Cow/horse } & \multicolumn{2}{|c|}{ Lagomorph } & \multicolumn{2}{|c|}{ Wild boar } & \multicolumn{2}{|c|}{ Guanaco } & \multicolumn{2}{|c|}{ Other mammals ${ }^{a}$} & \multirow{2}{*}{$\begin{array}{l}\text { Total } \\
\text { prey }\end{array}$} & \multirow{2}{*}{$\begin{array}{l}\text { Total } \\
\text { pellets }\end{array}$} \\
\hline & $\% F$ & $\% \mathrm{O}$ & $\% F$ & $\% O$ & $\% \mathrm{~F}$ & $\% O$ & $\% \mathrm{~F}$ & $\% \mathrm{O}$ & $\% \mathrm{~F}$ & $\% \mathrm{O}$ & $\% \mathrm{~F}$ & $\% \mathrm{O}$ & $\% F$ & $\% \mathrm{O}$ & & \\
\hline Remolinos & 2.6 & 2.6 & 97.4 & 97.4 & & & & & & & & & & & 38 & 38 \\
\hline Guanaco & 85.7 & 85.7 & & & 14.3 & 14.3 & & & & & & & & & 14 & 14 \\
\hline Covunco & 90.6 & 90.6 & & & 3.1 & 3.1 & 6.3 & 6.3 & & & & & & & 32 & 32 \\
\hline Fragua Grande & 53.5 & 92.0 & & & 11.6 & 20.0 & 34.9 & 60.0 & & & & & & & 43 & 25 \\
\hline Buitrera & 60.5 & 85.2 & & & 7.9 & 11.1 & 28.9 & 40.7 & & & & & 2.6 & 3.7 & 38 & 27 \\
\hline Fragua Chica & 50.0 & 85.4 & 1.4 & 2.4 & 8.6 & 14.6 & 40.0 & 68.3 & & & & & & & 70 & 41 \\
\hline Condorerita & 50.0 & 71.4 & & & 10.0 & 14.3 & 33.3 & 47.6 & & & & & 6.7 & 9.5 & 30 & 21 \\
\hline Pipilcura & 68.8 & 100.0 & & & 4.8 & 7.0 & 26.4 & 38.4 & & & & & & & 125 & 86 \\
\hline Huechahue & 18.1 & 23.6 & 69.4 & 90.9 & 1.4 & 1.8 & 2.8 & 3.6 & 1.4 & 1.8 & 4.2 & 5.5 & 2.8 & 3.6 & 72 & 55 \\
\hline Pichileufu & 45.2 & 82.4 & & & 16.1 & 29.4 & 38.7 & 70.6 & & & & & & & 31 & 17 \\
\hline Chaqueñita & 62.5 & 100.0 & & & & & 37.5 & 60.0 & & & & & & & 24 & 15 \\
\hline Total & 51.5 & 71.7 & 17.0 & 23.7 & 6.2 & 8.6 & 23.6 & 32.9 & 0.2 & 0.3 & 0.6 & 0.8 & 1.0 & 1.3 & 517 & 371 \\
\hline
\end{tabular}

${ }^{a}$ Mostly foxes and armadillos.

Frequency of prey items $(\% \mathrm{~F})$ expressed as percentages of the total number of prey. Frequency of occurrence $(\% \mathrm{O})$ is expressed as percentages of the total number of pellets. 


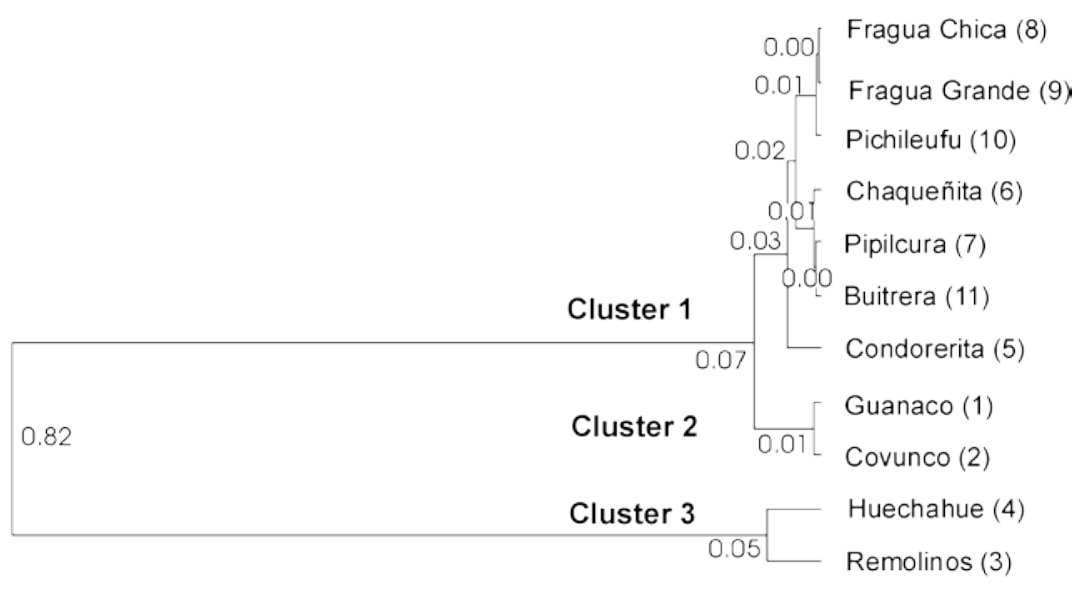

Figure 2 Cluster analysis dendrogram of the 11 studied sites in northern Patagonia, based on the similarity in the diet composition. The values of Ward's index of similarity are indicated at each bifurcation (see the main text for details). Numbers in brackets correspond to the map numbers (Fig. 1a).

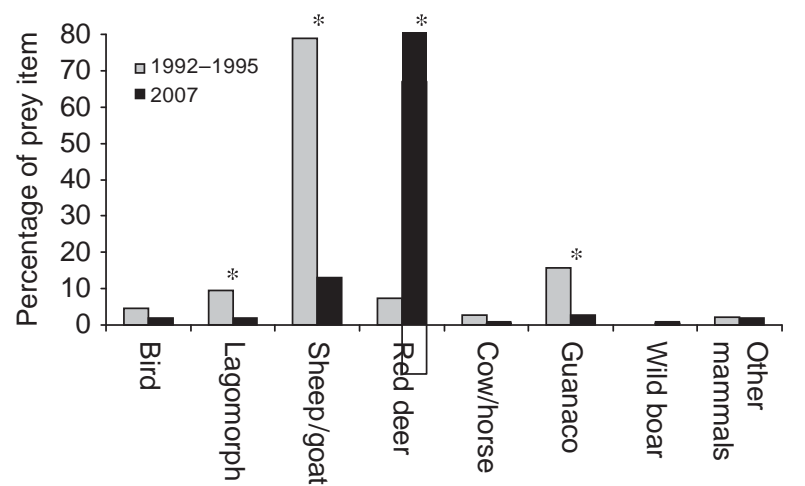

Figure 3 Temporal changes in the diet composition between summer 1992-1995 and 2007. Values represent the percentage occurrence of each item in relation to the total number of pellets. Statistical differences are marked with an asterisk ( $\left.{ }^{\mathrm{X}} \mathrm{P} \mathbf{0} 0.05\right)$.

\section{Discussion}

\section{Spatial and temporal differences in the diet composition}

Our study revealed that, at present, condors in Patagonia rely heavily on exotic mammals as their food source. More than $98 \%$ of the total prey was introduced herbivores. The most frequent food items were managed livestock (sheep and goats) and wild exotic mammals (lagomorphs and red deer). Another study performed in northern Patagonia to evaluate potential prey biomass available for mammalian carnivores concluded that introduced (domestic and wild) species comprise $94 \%$ of the total biomass, compared with only $6 \%$ of native species (Novaro et al., 2000). This disproportion is reflected in the diet of the two main carnivores of the region, the puma Felis concolor and the culpeo fox Pseudalopex culapaeus, which, in recent times, have shifted their diets towards introduced mammals (Novaro et al., 2000). As a consequence, it has been proposed that the two Patagonian mega-herbivores (guanaco and lesser rhea) are virtually ecologically extinct as prey
(Novaro et al., 2000; sensu Estes, Duggins \& Rathbun, 1989). Our results suggest that these two native herbivores are also ecologically extinct as sources of carrion for native scavengers.

Andean condors fed on seven of the nine exotic mediumlarge mammal species available in Patagonia (sensu Novillo \& Ojeda, 2008). The other alien species (two deer: Dama dama and Axis axis) may be in very low densities or use areas where condors cannot easily find their carcasses. Red deer was important in localities of the central part of the study area (Huechahue and Remolinos), where deer hunting is a common practice and its abundance is very high and increasing. At present, deer density in this area is estimated at around eight times the value of 1992-1994. Over the past decade, ranchers have killed a large number of red deer in an attempt to diminish the population of the species in that area. In this way, they reduce competition with their livestock, and maintain the best individuals of red deer for hunting (J. Sanguinetti, pers. comm.). The conjunction of increased deer population (thus more natural mortality) and increased hunting (either recreational or for control) yields more available deer carrion for condors than years ago.

Surprisingly, lagomorphs (especially hares) were very important as a foraging resource in the southern localities. Until now, there have been almost no previous records of condors eating hares in the area (Travaini et al., 1998; J. Bellati, pers. comm.; authors, pers. obs. ). An average adult hare weighs about $3.5 \mathrm{~kg}$, which undoubtedly constitutes an unprofitable food item for a large bird such as the condor. However, the abundance of hares in Patagonia (both in Argentina and Chile) has made it an important resource for top carnivores and scavengers (e.g. Pavez, Gonzalez \& Jimenez, 1992; Hiraldo et al., 1995; Donazar et al., 1997; Jaksic, 1998; Travaini et al., 1998; Novaro et al., 2000). Millions of hares are hunted and exported every year in Patagonia (see the review in Novillo \& Ojeda, 2008). A proportion of the individuals shot during the hunting season are not killed instantly, but escape and die later in the field, thus becoming available as a source of carrion for scavengers. Andean condors are probably taking advantage of this food supply. However, prey size could influence the 
aggregation patterns of a species; for example, communal roosting is not expected if the food is not large enough to be shared (see Beauchamp, 1999 for a review). The influence of the increase in the use of this small food source on condor sociality remains to be studied.

Temporal shifts in diet composition over long periods of time do not seem to be rare in condors (Chamberlain et al., 2005). However, it is interesting to see that important changes can occur over a short period of time (i.e. around a decade). Changes of the main prey items in the diet, increasing or decreasing their numbers, reflect the changes that these species underwent in the field ( Novaro et al., 2000; Amaya et al., 2001; Novaro \& Walker, 2005; authors, unpubl. data). Human changes in land use strongly affect the distribution and abundance of carcasses. Currently, in north-west Patagonia, the introduction of exotic species for livestock and hunting purposes has substituted native animals (Walker et al., 2005). In our study, the population shifted from one exotic species to another (from sheep to red deer), but the same changes had to have occurred previously between native and the first exotic species. Changes in the economy of Argentina and the international price of wool during the last decade led to the diminution in the sheep abundances that could have favoured the increase of the reed deer population, and hunting, and widening of its distribution. This short-term shift in prey selection should be taken into account when designing management strategies, since a strategy useful for a species in the present day could not be so in the near future.

Considering the early reports of condors feeding on guanacos and lesser rheas, the carrion consumed today shows that these birds are opportunistic, and their diet reflects the major changes in the fauna of Patagonia in recent times. The declining populations of native herbivores were substituted by introduced wild and domestic species, and carrion-eaters have taken advantage of them. Moreover, the similarity in diet composition of sites close together suggests that although condors can fly very long distances (Wallace \& Temple, 1987b; Lambertucci, 2007), they forage in the areas surrounding their communal roosts and may be in the same places. These results reinforce the idea of flexibility in the diet of this species, which is capable of adapting itself to changes in the availability of food sources at spatial and temporal scales. Besides the information on food type changes, our temporal variation data also suggest that food niche breadth decreased. This fact, in turn, could have important implications for the persistence of the species, given that it may increase the vulnerability of condors to extinction as they exclusively depend on a few species. However, we cannot generalize our results because our data on temporal variation come from only two places.

\section{Management of exotic and native species in a conservation strategy}

The management of introduced species (both wildlife and livestock) should take into account the species that depend on them. Populations of carrion-eater are mostly controlled bottom-up by available food resources. Therefore, the management of livestock, the importance of wild exotic species as a food source and the risk associated with its consumption should be acknowledged. Scavengers are subject to non-natural fluctuations because carcasses, as a food source, can disappear in a few years due to changes in management practices, the prices of livestock or changes in sanitary policies (Donazar, 1993; Tella, 2001; Gangoso et al., 2006). At the present time, Andean condors, as with vultures in Europe and Asia (Donazar, 1993; Oaks et al., 2004; Gangoso et al., 2006), depend on current policies on livestock and wild exotic species. Changes in the economy of the country and/or the world price of meat or wool, as well as the use of drugs in livestock and carcass poisoning to kill predators, all represent current threats to the condors.

Human activities such as hunting exotic species with lead bullets also pose very dangerous threats (see the review in Fisher, Pain \& Thomas, 2006). In Patagonia, deer and hares are legally hunted, which increases the amount of food availability, but also the risk of lead poisoning - not only for condors but for all the scavengers that feed on them (authors, unpubl. data). Populations of raptor scavengers are extremely sensitive to the availability of healthy food sources (i.e. free of lead bullets, poison, veterinarian drugs, etc.), because a high proportion of the population in an area may be eating from the same carcass (Donazar, 1993; Koenig, 2006; Lambertucci, 2007). Thus, entire populations of these scavengers may become extinct in a very short period of time if many individuals feed from a single 'unhealthy' carcass, as is happening with vultures across the world (Koenig, 2006). Antibiotics and anti-inflammatory drugs provided to livestock are currently major threats to scavengers (Blanco et al., 2007; Lemus et al., 2008). Indeed, they have recently been blamed for the extinction of populations of different vulture species (Oaks et al., 2004). It has been suggested that in order to avoid these kinds of problems, the native diet composition needs to be recovered (Chamberlain et al., 2005). Management strategies should be focused in each area depending on the risk condors have due to land use. Communal roosts located at the centre and south of the study area are more exposed to a risk of poisoning than the northern ones, given that deer hunting is a common practice in the former places. A strategy to avoid lead poisoning for those areas is necessary.

Our results on the Andean condor diet support the idea that the native guanacos and lesser rheas are no longer interacting with predators and scavengers in north-west Patagonia (Novaro et al., 2000). It is essential to halt the decline in native herbivores and re-establish their populations in Patagonia by eliminating hunting practices on native species, and reducing the densities of exotic species (Novaro et al., 2000; Walker et al., 2005). Complete exclusion of well-established and widely distributed species such as the European hare and red deer is probably not possible. Indeed, rapid and total exclusion of exotic species is not recommended, considering the strong dependence of Andean condors, other scavengers and top predators on these alien species. Exclusion of exotic species should be gradual, 
allowing the slow recovery of native species, taking into account the strong changes they produce in the ecosystem (Zavaleta et al., 2001). Nonetheless, some exotic species numbers (domestic and wild) in Patagonia continue to increase because they are being used as a resource for food, clothes, hunting, etc. Therefore, they are protected by laws and are considered a positive resource by the general public. On the contrary, native species are often less valuable, given they are not considered attractive to economic investments and are generally persecuted due to their competition with exotic and profitable livestock (Baldi et al., 2001). Changes in the valuation of native species are urgently needed. A strategy that includes serious productive plans, including native species as a suitable source of economic development (e.g. ecotourism, production, etc.), may help to change the current perspective. This strategy should involve public environmental education about the problems of the use of poison, and veterinary medicines, as well as about the importance of removing lead bullets from carcasses. Natural protected areas could also play a key role in this strategy as a source of native fauna for the recolonization of landscapes used by humans, for providing healthy food for carnivores and scavengers and for educational purposes.

\section{Acknowledgements}

We are grateful to Global Vision International volunteers and coordinators, F. Barbar and C. Lambertucci for field assistance during the collection of the samples. K. Speziale, A. Novaro, S. Walker, T. Rogers, C. Wells, V. Chalcoff, P. Fergnani and three anonymous reviewers provided valuable suggestions on an early version of the paper. J. Sanguinetti, M. Monteverde and M. Failla provided useful information. We thank the ANPCyT (PICT 38148BID1728/OC-AR) for financial support. The Argentinean National Park Administration, Rio Negro and Neuquen provinces gave permission to collect the samples. S.A.L. was funded by the Argentine research council CONICET during this work.

\section{References}

Amaya, J.N., von Thungen, J. \& De Lamo, D.A. (2001). Densidad de guanacos (Lama guanicoe) en la Patagonia. Comunicacion Tecnica No. 109, INTA, Bariloche.

Baldi, R., Albon, S.D. \& Elston, D.A. (2001). Guanacos and sheep: evidence for continuing competition in arid Patagonia. Oecologia 129, 561-570.

Beauchamp, G. (1999). The evolution of communal roosting in birds: origin and secondary losses. Behav. Ecol. 6, 675-687.

Blanco, G., Lemus, J.A., Grande, J., Gangoso, L., Grande, J.M., Donazar, J.A., Arroyo, B., Frıas, O. \& Hiraldo, F. (2007). Geographical variation in cloacal microflora and bacterial antibiotic resistance in a threatened avian scavenger in relation to diet and livestock farming practices. Environ. Microbiol. 9, 1738-1749.
Bonnet, E. \& Van de Peer, Y. (2002). ZT: a software tool for simple and partial Mantel tests. J. Stat. Software 7, $1-12$.

Byers, J.A. (1997). Surface distance between two points of latitude and longitude. USA: Agricultural Research Service. Available at http://www.chemical-ecology.net/java/latlong.htm (accessed 15 October 2008).

Carrete, M., Grande, J.M., Tella, J.L., Sanchez-Zapata, J.A., Donazar, J.A., Diaz-Delgado, R. \& Romo, A. (2007). Habitat, human pressure, and social behavior: partialling out factors affecting large-scale territory extinction in an endangered vulture. Biol. Conserv. 136, 143-154.

Chamberlain, C.P., Waldbauer, J.R., Fox-Dobbs, K., Newsome, S.D., Koch, P.L., Smith, D.R., Church, M.E., Chamberlain, S.D., Sorenson, K.J. \& Risebrough, R. (2005). Pleistocene to recent dietary shifts in California condors. Proc. Natl. Acad. Sci. USA 102, 16707-16711.

Chehebar, C. \& Martin, S. (1989). Guia para el reconocimiento de los pelos de los mamiferos de la Patagonia. Doñana Acta Vertebrata 16, 247-291.

Darwin, C. (1921). Diario del viaje de un naturalista alrededor del mundo en el navío de S. M., "Beagle"' (Trad. of the Voyage of the Beagle, 1837). Tomo I. Madrid: Calpe.

De Marinis, A.M. \& Asprea, A. (2006). Hair identification key of wild and domestic ungulates from southern Europe. Wildl. Biol. 12, 305-320.

Donazar, J.A. (1993). Los buitres Ibéricos: Biología y Conservación. Madrid, Spain: Ed. Reyero.

Donazar, J.A., Travaini, A., Ceballos, O., Delibes, M. \& Hiraldo, F. (1997). Food habits of the Great Horned Owl in northwestern Argentine Patagonia: the role of introduced lagomorphs. J. Raptor Res. 31, 364-369.

Donazar, J.A., Travaini, A., Ceballos, O., Rodrıguez, A., Delibes, M. \& Hiraldo, F. (1999). Effects of sex-associated competitive asymmetries on foraging group structure and despotic distribution in Andean condors. Behav. Ecol. Sociobiol. 45, 55-65.

Estes, J.A., Duggins, D.O. \& Rathbun, G.B. (1989). The ecology of extinctions in kelp forest communities. Conserv. Biol. 3, 252-264.

Ferguson-Lees, J. \& Christie, D.A. (2001). Raptors of the world. London: Christopher Helm.

Fisher, I.J., Pain, D.J. \& Thomas, V.G. (2006). A review of lead poisoning from ammunition sources in terrestrial birds. Biol. Conserv. 131, 421-432.

Foley, J.A., DeFries, R., Asner, G.P., Barford, C., Bonan, G., Carpenter, S.R., Chapin, F.S., Coe, M.T., Daily, G.C., Gibbs, H.K., Helkowski, J.H., Holloway, T., Howard, E.A., Kucharik, C.J., Monfreda, C., Patz, J.A., Prentice, I.C., Ramankutty, N. \& Snyder, P.K. (2005). Global consequences of land use. Science 309, 570-574.

Gangoso, L., Donazar, J.A., Scholz, S., Palacios, C.J. \& Hiraldo, F. (2006). Contradiction in conservation of island ecosystems: plants, introduced herbivores and avian scavengers in the Canary Islands. Biodiver. Conserv. 15, 2231-2248. 
Gauch, H.G. (1999). Multivariate analysis in community ecology. Cambridge: Cambridge Studies in Ecology, Cambridge University Press.

Giacosa, R.E., Alfonso, J.C., Heredia, N. \& Paredes, J. (2005). Tertiary tectonics of the sub-Andean region of the North Patagonian Andes, southern central Andes of Argentina (41-42130 S). J. S. Am. Earth Sci. 20, 157-170.

Grigera, D.E. \& Rapoport, E.H. (1983). Status and distribution of the European hare in South America. J. Mammal. 64, 163-166.

Harveson, P.M., Lopez, R.R., Collier, B.A. \& Silvy, N.J. (2007). Impacts of urbanization on Florida Key deer behavior and population dynamics. Biol. Conserv. 134, 321-331.

Hiraldo, F., Donazar, J.A., Ceballos, O., Travaini, A., Bustamante, J. \& Funes, M. (1995). Breeding biology of a Grey Eagle-Buzzard population in Patagonia. Wilson Bull. 107, 675-685.

INDEC. (2002). Censo Nacional Agropecuario. Instituto Nacional de Estadisticas y Censos. Available at http:// www.indec.mecon.gov.ar (accessed 20 October 2008).

International Union for the Conservation of Nature. (2007). 2007 IUCN Red List of Threatened Species. Available at http://www.iucnredlist.org (accessed 20 October 2008).

Jaksic, F.M. (1998). Vertebrate invaders and their ecological impact in Chile. Biodivers. Conserv. 7, 1427-1445.

Koenig, R. (2006). Vulture research soars as the scavengers' numbers decline. Science 312, 1591-1592.

Lambertucci, S.A. (2007). Biologia y conservacion del Condor Andino (Vultur gryphus) en Argentina. Hornero 22, 149-158.

Lambertucci, S.A., Jacome, N.L. \& Trejo, A. (2008). Use of communal roosts by Andean Condors in northwest Patagonia, Argentina. J. Field Ornithol. 79, 138-146.

Lambertucci, S.A., Speziale, K.L., Roggers, T.E. \& Morales, J.M. (2009). How do roads affect the habitat use of an assemblage of scavenging raptors? Biodivers. Conserv. (DOI: 10.1007/s10531-008-9573-3).

Lemus, J.A., Blanco, G., Grande, J., Arroyo, B., GarcıMontijano, M. \& Martınez, F. (2008). Antibiotics threaten wildlife: circulating quinolone residues and disease in avian scavengers. PLoS One 3, e1444.

Matheron, G. (1963). Principles of geostatistics. Econ. Geol. 58, 1246-1266.

Moreno, F.P. (1969). Viaje a la Patagonia austral 1876-1877. Buenos Aires: Solar/Hachette.

Musters, G.C. (2005). Vida entre los Patagones (Trad. of at home with the Patagonians, 1871). El Elefante Blanco: Buenos Aires.

Novaro, A.J., Funes, M.C. \& Walker, R.S. (2000). Ecological extinction of native prey of a carnivore assemblage in Argentine Patagonia. Biol. Conserv. 92, 25-33.

Novaro, A.J. \& Walker, R.S. (2005). Human-induced changes in the effect of top carnivores on biodiversity in the Patagonian steppe. In Large carnivores and the conservation of biodiversity: 268-288. Ray, J.C., Redford, K.H., Steneck, R.S. \& Berger, J. (Eds). Washington, DC: Island Press.

Novillo, A. \& Ojeda, R.A. (2008). The exotic mammals of Argentina. Biol. Invas. 10, 1333-1344.

Oaks, J.L., Gilbert, M., Virani, M.Z., Watson, R.T., Meteyer, C.U., Rideout, B.A., Shivaprasad, H.L., Ahmed, S., Chaudhry, M.J.I., Arshad, M., Mahmood, S., Ali, A. \& Khan, A.A. (2004). Diclofenac residues as the cause of vulture population decline in Pakistan. Nature 427, 630-633.

Paruelo, J.M., Beltran, A., Jobbagy, E., Sala, O.E. \& Golluscio, R.A. (1998). The climate of Patagonia: general patterns and controls on biotic processes. Ecología Austral 8, 85-101.

Pavez, E.F., Gonzalez, C.A. \& Jimenez, J.E. (1992). Diet shifts of black-chested eagles (Geranoaetus melanoleucus) from native prey to European rabbits in Chile. J. Raptor Res. 26, 27-32.

Rios-Uzeda, B. \& Wallace, R.B. (2007). Estimating the size of the Andean Condor population in the Apolobamba Mountains of Bolivia. J. Field Ornithol. 78, 170-175.

Sanchez-Zapata, J.A., Carrete, M., Gravilov, A., Sklyarenko, S., Ceballos, O., Donazar, J.A. \& Hiraldo, F. (2003). Land use changes and raptor conservation in steppe habitats of Eastern Kazakhstan. Biol. Conserv. 111, 71-77.

Speziale, K.L., Lambertucci, S.A. \& Olsson, O. (2008). Disturbance from roads negatively affects Andean Condor habitat use. Biol. Conserv. 141, 1765-1772.

Tella, J.L. (2001). Action is needed now, or BSE crisis could wipe out endangered birds of prey. Nature 410, 408.

Travaini, A., Donazar, J.A., Rodriguez, A., Ceballos, O., Funes, M., Delibes, M. \& Hiraldo, F. (1998). Use of European hare (Lepus europaeus) carcasses by an avian scavenging assemblage in Patagonia. J. Zool. 246, 175-181.

Walker, S., Novaro, A., Funes, M., Baldi, R., Chehebar, C., Ramilo, E., Ayesa, J.A., Bran, D.E., Vila, A.R. \& Bonino, N.A. (2005) Rewilding Patagonia: in the wild Patagonia reserve network, guanacos, choiques, and pumas will roam free. Wildlands Project: 36-41, Wild Earth, USA.

Wallace, M.P. \& Temple, S.A. (1987a). Competitive interactions within and between species in a guild of avian scavengers. Auk 104, 290-295.

Wallace, M.P. \& Temple, S.A. (1987b). Releasing captivereared Andean Condors to the wild. J. Wildl. Mgmt. 51, 541-550.

Wallace, M.P. \& Temple, S.A. (1988). Impacts of the 1982-1983 El Nino on population dynamics of Andean Condors in Peru. Biotropica 20, 144-150.

Ward, J.H. (1963). Hierarchical grouping to optimize an objective function. J. Am. Stat. Assoc. 58, 236-244.

Zavaleta, E.S., Hobbs, R.J. \& Mooney, H.A. (2001). Viewing invasive species removal in a whole-ecosystem context. Trends Ecol. Evol. 16, 454-459. 